\title{
自作の第四脳室底刺激プローブについて
}

\author{
山口由太郎，小野元，関野 宏明
}

\section{Custom-made Stimulation Probes for the Intraoperative Stimulation of the Fourth Ventricle Floor}

\author{
Yoshitaro Yamaguchi, M.D., Hajime Ono, M.D., and Hiroaki Sekino, M.D. \\ Department of Neurosurgery, St. Marianna University School of Medicine, Kawasaki, Japan
}

Summary: We customized and used stimulation probes (SP) for the intraoperative stimulation of the fourth ventricle floor (IoS). The facial nerve was intraoperatively monitored 7 times prior to resection of 6 cavernous angiomas in the pons and puncture of 1 cystic metastatic tumor in the pons during 3 years. We made 5 types of SP, which were composed of handpiece and electrode. From No.1 to No.5, they were improved for IoS. Both adequate manipulation of handpiece, electrode and proper flexibility of electrode were required to provide precise and safe stimulation of the intended site. The latest SP, No.5 made from the steel handpiece and silver-ball electrode coated with silicon is improved in several ways and is best suited for IoS.

\section{はじめに}

1992 年以降, 第四脳室底術中刺激の有用性・重要性が報 告されている ${ }^{1-6)}$. しかし, 実施に当たっては問題点・不 明点があり，一般的モニターとなっていないのが現状であ る. 第四脳室底術中刺激の成否はハードウェアにかかり, その中でも刺激プローブが成否を左右するといっても過言 ではない，そこで，数回の改良の結果，実用となったわれ われの刺激プローブを紹介する.

\section{対象および方法}

平成 6 年 6 月から平成 9 年 12 月までの間に, 6 例に計 7 回第四脳室底術中刺激を行った。疾患は橋海綿状血管腫 5

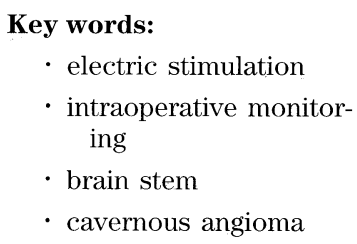

Surg Cereb Stroke (Jpn) 27: 472-478, 1999 例・転移性橋腫瘍 1 例である(Table 1)。刺激プローブは である(ユニークメディカル，東京）。把持部はステンレ 聖マリアンナ医科大学 脳神経外科(受稿日 1998.12.9)〔連絡先：テ215-8511 神奈川県川崎市宮前区菅生 2-16-1 聖マリアンナ医科大 学 脳神経外科 山口由太郎〕〔Mailing address: Yoshitaro Yamaguchi, M.D., Department of Neurosurgery, St. Marianna University School of Medicine, 2-16-1 Sugao, Miyamae-ku, Kawasaki, Kanagawa 215-8511, Japan] 
Table 1 Summary of clinical characteristics and the results of intraoperative monitorings in 7 patients

\begin{tabular}{|c|c|c|c|c|c|c|c|}
\hline \multirow{2}{*}{ Case } & \multirow{2}{*}{$\begin{array}{l}\text { Age } \\
\text { Gender }\end{array}$} & \multirow{2}{*}{ Disease } & \multirow{2}{*}{ Side } & \multirow{2}{*}{$\begin{array}{c}\text { Preoperative } \\
\text { facial nerve palsy }\end{array}$} & \multicolumn{3}{|c|}{ CMAP } \\
\hline & & & & & Or.Oculi & Or.Oris & Tongue \\
\hline 1 & $42 / F$ & $\begin{array}{c}\text { Cavernous } \\
\text { angioma }\end{array}$ & Left & None & $\stackrel{+}{0.5 \mathrm{~mA}}$ & $\stackrel{+}{0.5 \mathrm{~mA}}$ & $0 . \overline{5 \mathrm{~mA}}$ \\
\hline 2 & $42 / F$ & $\begin{array}{c}\text { Cavernous } \\
\text { angioma }\end{array}$ & Left & Complete & $0 . \overline{\mathrm{mA}}$ & $0 . \overline{5 \mathrm{~mA}}$ & Not exam. \\
\hline 3. & $29 / F$ & $\begin{array}{c}\text { Cavernous } \\
\text { angioma }\end{array}$ & Left & Complete & $\stackrel{+}{+} \stackrel{+}{5 \mathrm{~mA}}$ & $\begin{array}{c}+ \\
0.5 \mathrm{~mA}\end{array}$ & Not exam. \\
\hline 4 & $24 / M$ & $\begin{array}{c}\text { Cavernous } \\
\text { angioma }\end{array}$ & Right & Moderate & $1 . \overline{\mathrm{mA}}$ & $1 . \overline{5 \mathrm{~mA}}$ & Not exam. \\
\hline 5 & $27 / M$ & $\begin{array}{c}\text { Cavernous } \\
\text { angioma }\end{array}$ & Right & Complete & $0 . \overline{5 \mathrm{~mA}}$ & $0 . \overline{5 m A}$ & Not exam. \\
\hline 6 & $44 / F$ & $\begin{array}{l}\text { Cavernous } \\
\text { angioma }\end{array}$ & Right & Complete & $\frac{-}{0 .} \mathrm{mA}$ & $\frac{-}{0 .} \mathrm{mA}$ & Not exam. \\
\hline 7 & $46 / F$ & $\begin{array}{c}\text { Cavernous } \\
\text { angioma }\end{array}$ & Left & None & $\stackrel{+}{0.5 \mathrm{~mA}}$ & $\stackrel{+}{0.5 \mathrm{~mA}}$ & $0 . \overline{5 \mathrm{~mA}}$ \\
\hline
\end{tabular}

CMAP: Compound Muscle Action Potential Or. Oculi: Orbicularis Oculi

Or.Oris: Orbicularis Oris

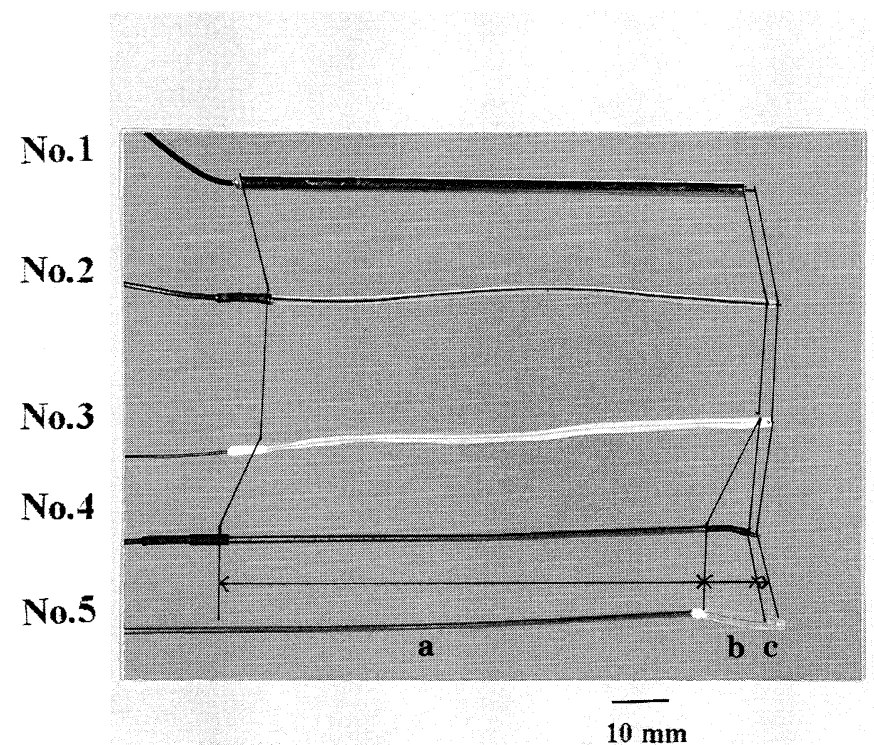

Fig. 1 Photographs of our custom-made probes which are composed of handpiece (a), connect (b) and electrode (c). Left is whole appearance, right is magnification view of electrode and connect.

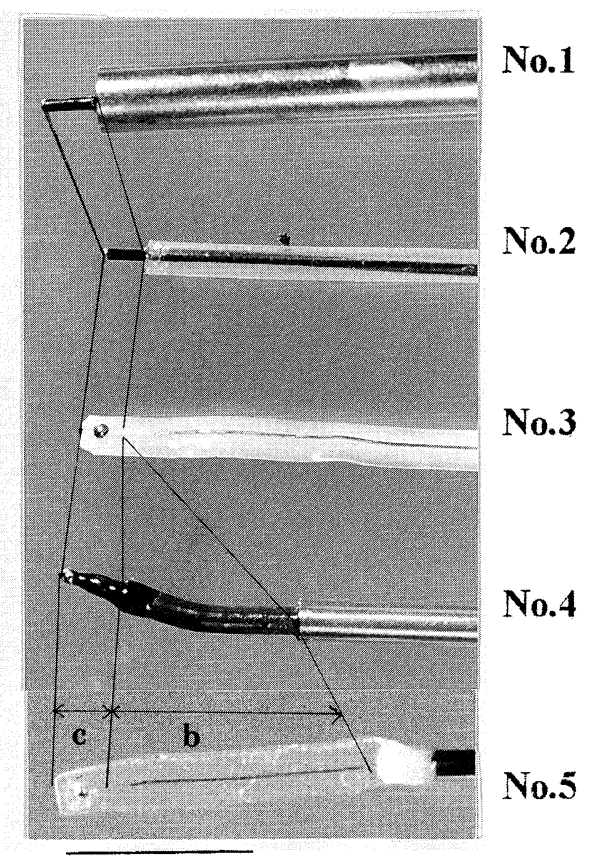

$10 \mathrm{~mm}$
ス製，先端部分 $2 \mathrm{~mm}$ を白金棒電極とした(Fig. 1, Table 2). 症例 1 (Fig. 2) に使用し, 第四脳室底の膨隆した部位 を中心に刺激した。刺激強度 $0.5 \mathrm{~mA}$ で刺激すると 3 力所 でCMAP陽性となった。この3カ所を結ぶ仮想線を引き 顔面神経の走行部位と推定した。その尾部で正中から左へ $5 \mathrm{~mm}$ 離れた部位に $5 \mathrm{~mm}$ の縦切開を加え血管腫を摘出し た. 最終的に切開線は $7 \mathrm{~mm}$ となった（以後の症例も同様
の方法で摘出した).この刺激電極の問題点は, プローベ 把持部から電極部分への径の変化が大きく, 電極部分が短 いため, 電極先端がまったくみえなかったことであった. そのため電極が第四脳室底に接触しているか判断しがた く, 持続刺激の際には同じ刺激部位を維持しにくいだけで なく第四脳室底損傷を起こしやすいという欠点が明らかと なった. No. 2 も白金棒電極である(ユニークメディカル, 

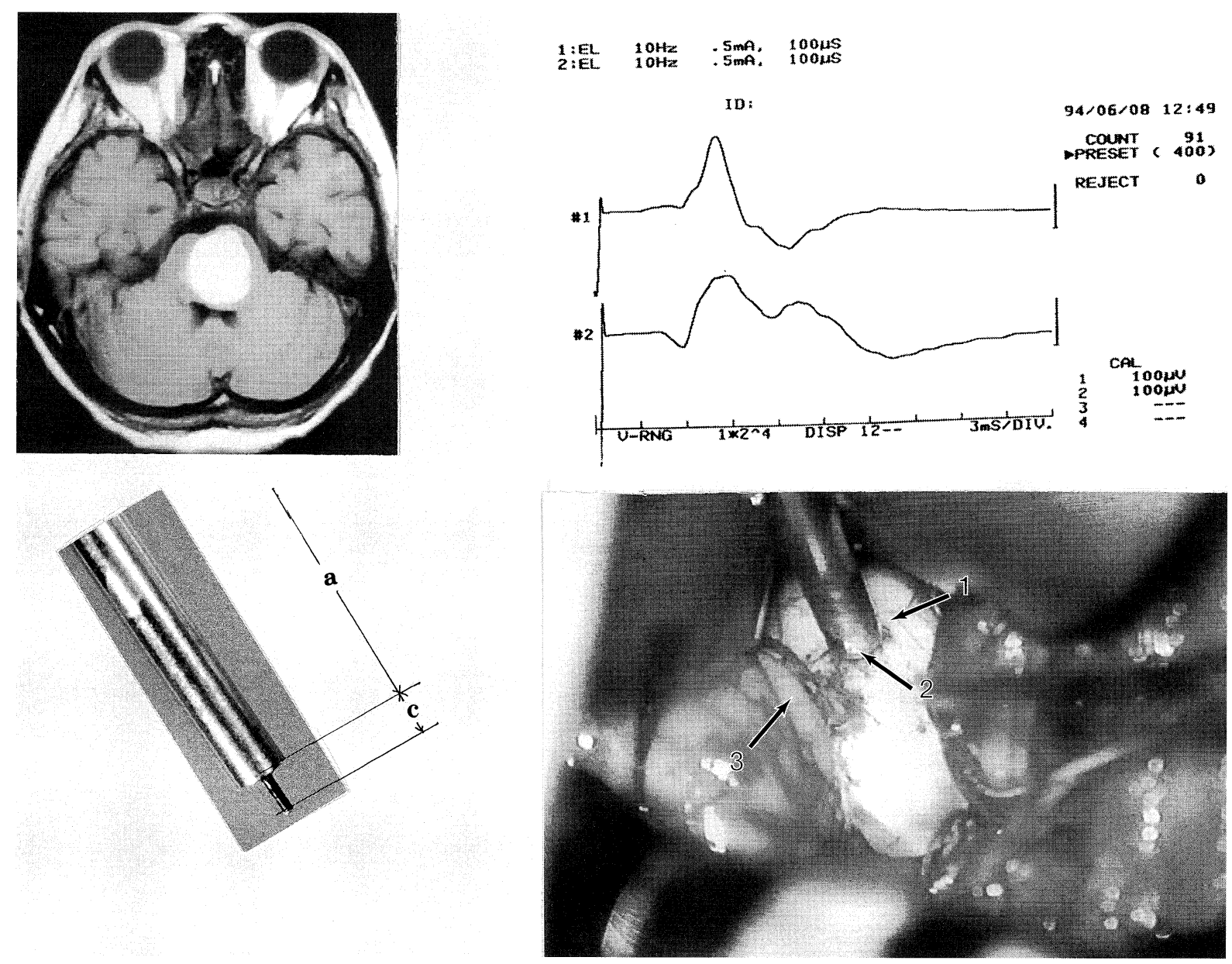

Fig. 2 No.1 stimulation probe and Case 1, left upper: Preoperative T1-weighted axial image, left lower: No. 1 stimulation probe, a: handpiece, c: electrode,

right upper: Record of CMAPs, orbicularis oculi muscle (upper line) and orbicularis oris muscle (lower line), right lower: Intraoperative photograph showing the No. 1 stimulation probe $(2), 1$ : left half of the fourth ventricle floor, 3: left tonsil

東京).No.10欠点を改善するために，把持部のステンレ スをシリコンチューブに変えることで柔軟性を増し，さら に電極部への径の変化を少なくした (Fig. 1, Table 2)。症 例 4 (Fig. 3) に使用し同様の方法で顔面神経の局在を確定 できたが，改良できた点は視野を妨げない点のみで，電極 部分は依然として固く第四脳室底損傷を起こしやい点は変 化がなかった. No. 3 以後は電極による第 4 脳室損傷を避 ける目的で銀ボール電極を採用した.No. 3 は(インターメ ディカル，東京), 電極を銀ボール電極にしただけでなく, 把持部をシリコンコーティングした銅線にしピンセットで 把持するように改良した(Fig. 1，Table 2)。症例 5(Fig. 4) に使用したが，第四脳室底損傷はなくなった一方で把持部 分が柔らかすぎ操作性が消失した結果，目標部位へ電極を 当てられなくなった。 No.4は（インターメディカル，東 京)，No. 3 の欠点を改良するために把持部分をステンレス
製・把持部分一電極間をヴィニール製・電極部分をシリコ ンコーティングした銀ボール電極とした (Fig. 1, Table 2). その結果, 操作性は改良できたが, 把持部分一電極間のヴ イニール部分が固くなりすぎ，逆に第四脳室底損傷を起こ やすいという問題が生じたため使用しなかった。No. 5 は (インターメディカル, 東京), 操作性を改良するために把 持部をNo.4，刺激部位をNo. 3 とした (Fig. 1, Table 2). 症例 7 (Fig. 5) に使用した結果, 把持しやすく, 意図した 部位に刺激プローブを当て維持することが可能となった. その結果, 第凹脳室底損傷を起こさず顔面神経の部位確定 が短時間で可能となった。

\section{考察}

MRIによる局在診断の進歩とともに脳幹内病変に対す る第四脳室底経由による摘出術が安全に行われるようにな 
Table 2 Features of our custom-made probes

A: Materials of handpiece and electrode

\begin{tabular}{llcc}
\hline Version and lead & \multicolumn{1}{c}{ Handpiece } & Connect & Electrodes \\
\hline No. 1: CuW/PVC & CuW/PVC/Stainless & None & $\mathrm{Pt}$ \\
No. 2: CuW/PVC & $\mathrm{CuW} /$ Insulation Coat/Stainless & None & $\mathrm{Pt}$ \\
No. 3: CuW/PVC & $\mathrm{CuW} / \mathrm{Si}$ & None & $\mathrm{Ag} / \mathrm{Si}$ \\
No. 4: CuW/PVC & $\mathrm{CuW} / \mathrm{Si} /$ Stainless & $\mathrm{CuW} / \mathrm{PVC}$ & $\mathrm{Ag} / \mathrm{Si}$ \\
No. 5: CuW/PVC & $\mathrm{CuW} / \mathrm{Si}$ Stainless & $\mathrm{CuW} / \mathrm{Si}$ & $\mathrm{Ag} / \mathrm{Si}$ \\
\hline
\end{tabular}

CuW: Cupper Wire, Si: Silicon Coating, Ag: Silver-ball PVC: Poly Vinyl Chloride, Pt: Platinum

B: Characteristics of probes

\begin{tabular}{c|c|cc}
\hline & Handpiece & \multicolumn{2}{|c}{ Electrodes } \\
\cline { 2 - 4 } & Manipulation & Manipulation & Flexibility \\
\hline No. 1 & $\times$ & $\times$ & $\times$ \\
No. 2 & $\triangle$ & $\times$ & $\times$ \\
No.3 & $\times$ & $\times$ & $\bigcirc$ \\
No. 4 & $\bigcirc$ & $\times$ & $\triangle$ \\
No. 5 & $\bigcirc$ & $\bigcirc$ & $\bigcirc$ \\
\hline
\end{tabular}
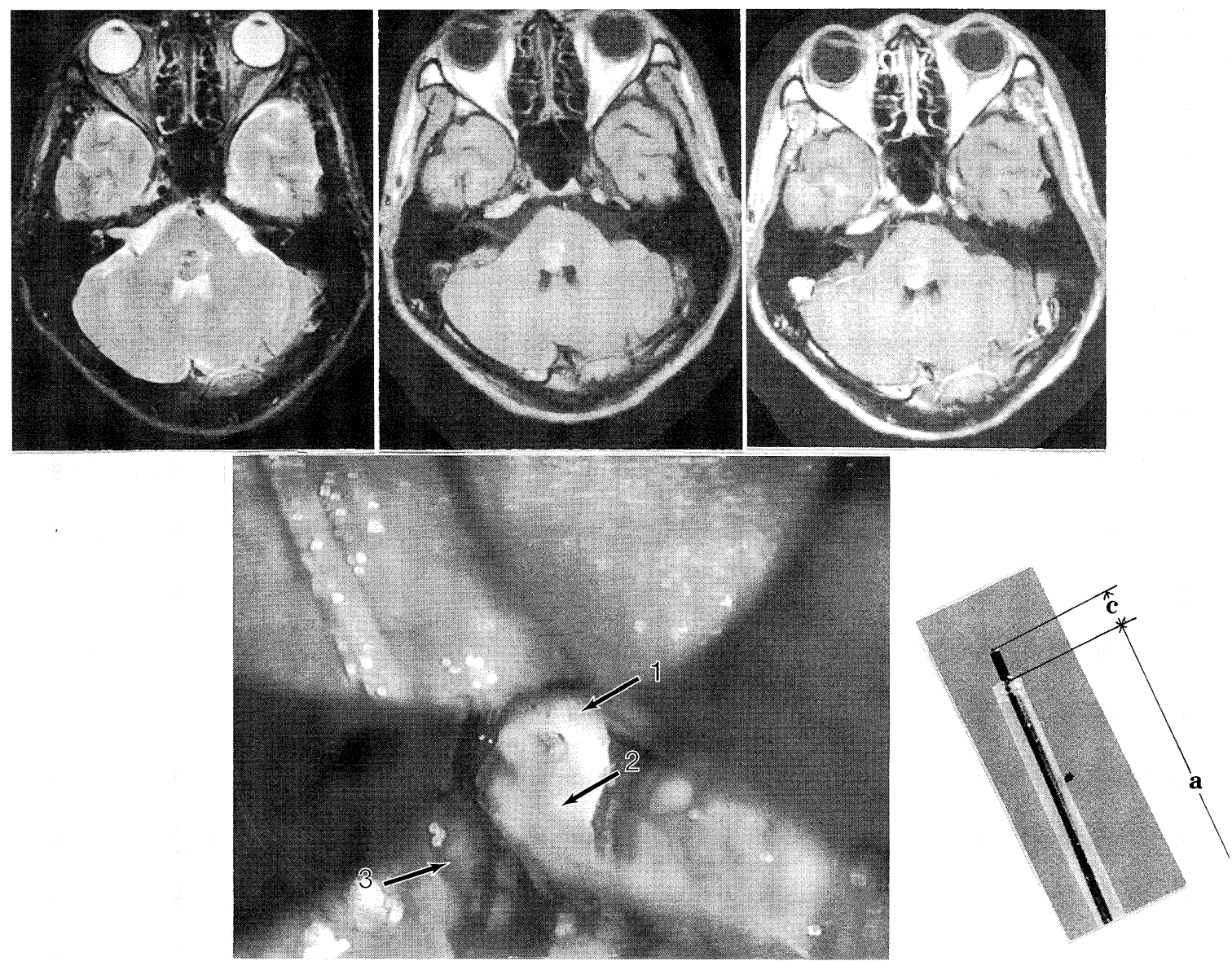

Fig. 3 No.2 stimulation probe and Case 4, upper: Preoperative axial MRI (T2-, T1- and enhanced T1-weighted images from left to right), lower left: Intraoperative photograph showing the No.2 stimulation probe (2) contacting right half of the fourth ventricle floor (1), 3: left tonsil, lower right: No.2 stimulation probe 


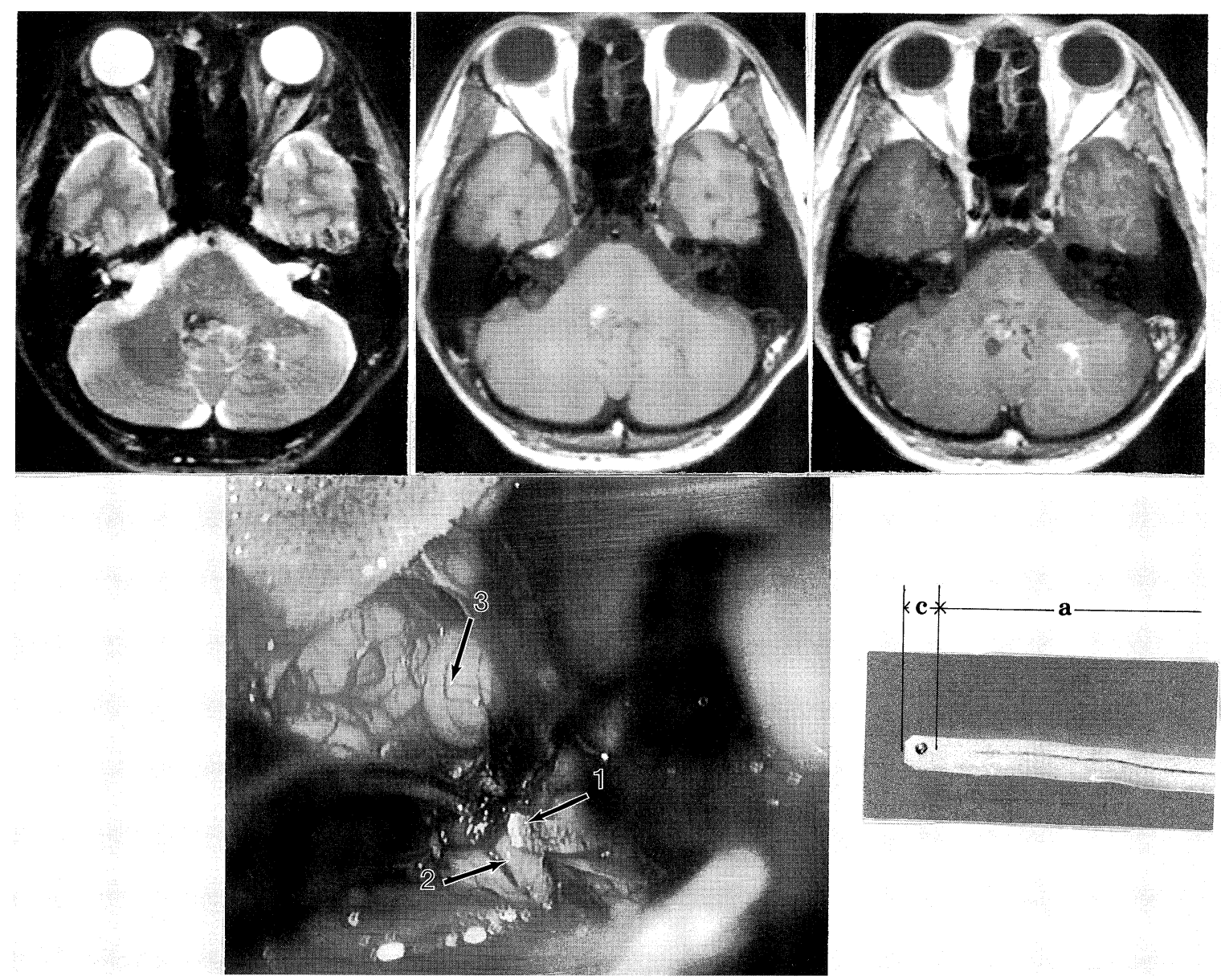

Fig. 4 No.3 stimulation probe and Case 5, upper: Preoperative axial MRI (T2-, T1-, and enhanced T1-weighted images from left to right), lower left: Intraoperative photograph showing No.3 stimulation probe (1) contacting right half of the fourth ventricle floor (2), 3: right tonsil, lower right: No.2 stimulation probe

っている。しかし, surgical morbidityは第四脳室底の進 入部位・摘出方法に左右されることは間違いない.

現在まで，進入部位を決定する方法は解剖学的分析と神経 生理学的分析の 2 方法が報告されている ${ }^{1-3)} 5^{-7)}$. 解剖学的 分析による進入部位は, (1)第四脳室底の最も突出した部位, または(2) Kyoshima ら ${ }^{4)} の$ median sulcus, stria medullaris, facial colliculusなどから想定される supra-, infra-facial trianglesである。神経生理学的分析は第四脳室底刺激によ る顔面・舌・軟口盍筋の肉眼的観察 · $\mathrm{EMG} \cdot \mathrm{CMAP}$ で ある. Strauss ${ }^{8)}$ は, 第四脳室底が突出し薄くなってい る部位でも EMG，CMAPが出現することがあるため，第 四脳室底に切開を加える際には第四脳室底刺激を行わなけ ればならないとしている。

第四脳室底の電気刺激は 1992 年 Rusyniak $ら^{6)}$ の報告が 最初でいまだ 7 年の経過である。具体的な方法は報告者間 で大きな違いはないが, 刺激プローブについては明確な記
載がないか，あっても実用的でない電極であったりしてい る (Table 3). われわれも報告例を参考に刺激プローブを 作成したが, 把持部の操作性, 電極部の柔軟性・操作性に 問題があった. 目的部位を正確に持続的に刺激でき・第四 脳室底損傷を起こしにくいという点を改良するために 5 回 の試作を要した。その結果，現在の刺激電極が完成し，第 四脳室底術中刺激が容易にできるようになった。

\section{結 論}

刺激プローブ把持部の操作性・電極部の柔軟性および操 作性を改良し，安全・正確な術中刺激が可能となった。

\section{文献}

1）江口恒良：橋海綿状血管腫の手術一術中モニタリングの有 用性一. 脳卒中の外科 22: 363-367, 1994

2) Eisner W, Schmid UD, Reulen HJ, et al: The mapping and continuous monitoring of the intrinsic motor neclei dur- 


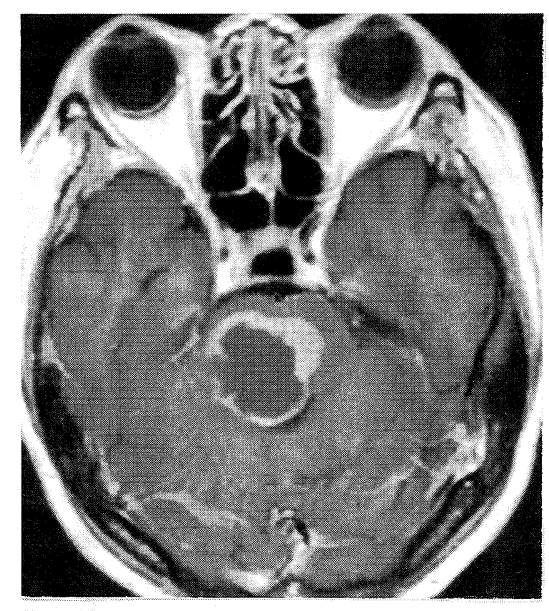

1:Ee $\quad \begin{aligned} & 10 \mathrm{~Hz} \\ & \text { 2: }\end{aligned}$
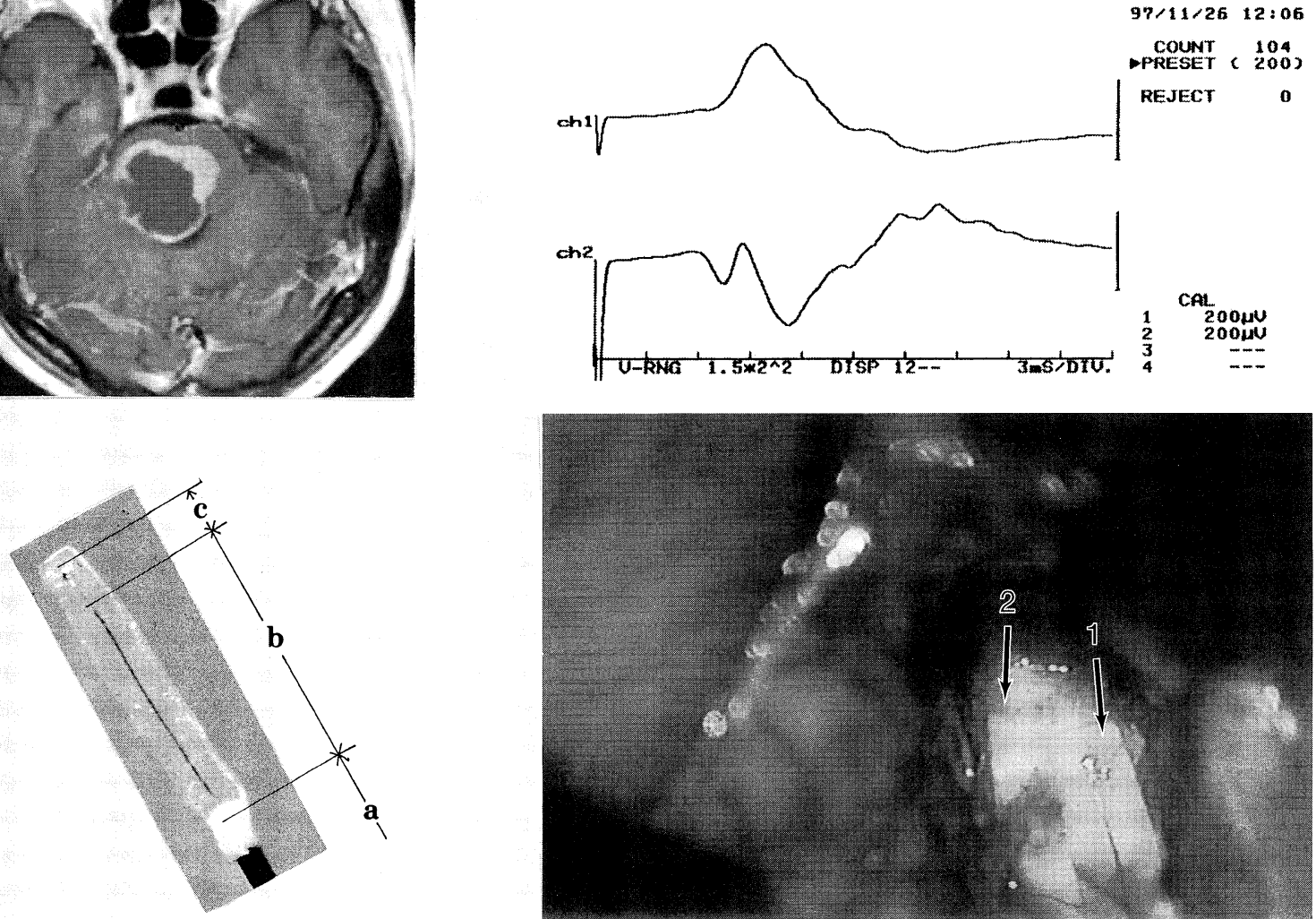

Fig. 5 No.5 stimulation probe and Case 7, left upper: Preoperative enhanced T1-weighted axial image, left lower: magnification of the probe tip, a: handpiece, b: connect, c: electrode, right upper: Record of CMAPs, orbicularis oculi muscle (upper line) and orbicularis oris muscle (lower line), right lower: Intraoperative photograph showing No.5 stimulation probe (1) precisely contacting the intended site of right half of the fourth ventricle floor (2)

Table 3 Stimulators and stimulation probes described on literatures

\begin{tabular}{|c|c|c|}
\hline Authors & Stimulators & Probes \\
\hline $\begin{array}{l}\text { Rusybiak WG et al. } \\
\text { (1992) }\end{array}$ & $\begin{array}{l}\text { Xomed Nerve Integrity } \\
\text { Monitoring-2 (Xomed) }\end{array}$ & $\begin{array}{l}\text { Xomed Monoplolar } \\
\text { Stimulating Probe }\end{array}$ \\
\hline $\begin{array}{l}\text { Strauss C et al. } \\
\text { (1993) }\end{array}$ & $\begin{array}{l}\text { Pathfinder I Stimulation } \\
\text { Unit (Nicolet) }\end{array}$ & $\begin{array}{l}\text { Silicon-Embedded Electrodes } \\
\text { Custom-Made }\end{array}$ \\
\hline Katsuta et al. & $?$ & Silver Ball Electrodes \\
\hline $\begin{array}{l}\text { Eguchi T } \\
\text { (1994) }\end{array}$ & $\begin{array}{l}\text { SMP-3100 } \\
\text { (Nihon Kohden) }\end{array}$ & Silver Ball Electrodes \\
\hline $\begin{array}{l}\text { Morota N et al. } \\
\text { (1995) }\end{array}$ & $\begin{array}{l}\text { Axon Sentinel-4 } \\
\text { Evoked potential EEG System }\end{array}$ & $\begin{array}{l}\text { Xomed No.82-25100 } \\
\text { with } 0.75 \mathrm{~mm} \text { Diameter Tip }\end{array}$ \\
\hline $\begin{array}{l}\text { Eisner W et al. } \\
(1995)\end{array}$ & $\begin{array}{l}\text { Viking II } \\
\text { (Nicolet) }\end{array}$ & $\begin{array}{l}\text { Needle Electrodes } \\
\text { Custom-Made, Non-Insulated }\end{array}$ \\
\hline $\begin{array}{l}\text { Yamaguchi Y et al. } \\
\text { (1998) }\end{array}$ & $\begin{array}{l}\text { Synax } 1100 \\
\text { (NEC Medical) }\end{array}$ & $\begin{array}{l}\text { Silver Ball Electrodes } \\
\text { Custom-Made }\end{array}$ \\
\hline
\end{tabular}


ing brain stem surgery. Neurosurgery 37: 255-265, 1995

3) Katsuta T, Morioka T, Fujii K, et al: Physiological localization of the facial colliculus during direct surgery on an intrinsic brain stem lesion. Neurosurgery 32: 861-863, 1993

4) Kyoshima K, Kobayashi, Gibo H, et al: A study of safe entry zone via the floor of the fourth ventricle for brainstem lesions. J Neurosurg 78: 987-993, 1993

5) Morota N, Vedran D, Spstein FJ, et al: Brain stem mapping: Neurophysiological localization of motor nuclei in the floor of the fourth ventricle. Neurosurgery 37: 922-930,
1995

6) Rusyniak WG, Patrick D, Radley MG, et al: Ultrasonographic and electrophysiological adjuncts to surgery within the brain stem: Technical note. Neurosurgery 31: 798-801, 1992

7）関谷徹治, 鈴木重晴：脳幹部手術の電気生理学的術中モ二 タリング. 脳神経外科 24: 311-320, 1996

8) Straus C, Romstock J, Nimsky C, et al: Intraoperative identification of motor areas of the rhomboid fossa using direct stimulation. J Neurosurg 79: 393-399, 1993 